\title{
MEDIAÇÃOCOMOINSTRUMENTODEEMANCIPAÇÃO E DE CIDADANIA
}

\section{Mediation as an instrument of emancipation and citizenship}

\section{Caroline Wüst}

Mestra em Direito na Área de Concentração Direitos Sociais e Políticas Públicas pela Universidade de Santa Cruz do Sul, UNISC. Especialista em Direito Tributário pela Universidade para o Desenvolvimento do Estado e da Região do Pantanal, UNIDERP, Brasil. Graduada em Direito pela Universidade Regional Integrada do Alto Uruguai e das Missões, URI, Câmpus Erechim. Advogada. Mediadora Judicial e extrajudicial nas áreas cível e de família. Membro da Comissão de Mediação da Ordem dos Advogados do Brasil, subseção Passo Fundo. Docente do Instituto Meridional, IMED, Passo Fundo.

\begin{abstract}
Resumo
Objetiva a presente pesquisa analisar a mediação como mecanismo de tratamento de conflitos que possibilita às partes envolvidas a escolha de seus destinos, ou seja, além de ser promotora da democracia e uma forma de exercício da cidadania, ela emancipa o sujeito. Assim, primeiramente, se analisará o conflito na sociedade contemporânea e as formas de tratamento. Na sequência, será estudada a democracia e a cidadania, a partir da qual o cidadão tem o condão de gerir e decidir suas controvérsias de maneira autônoma e independente. E, por fim, examinar-se-á a mediação como instrumento de emancipação e de exercício da cidadania, cuja finalidade é demonstrar que o cidadão, através do diálogo participa ativamente do tratamento dos conflitos que são inerentes a vida em sociedade de forma democrática. Para tanto, utilizou-se o método de abordagem dedutivo e a técnica de pesquisa indireta por meio da pesquisa bibliográfica.
\end{abstract}

Palavras-chave: Cidadania. Conflitos. Democracia. Emancipação. Mediação.

\section{Abstract}

The objective of this research is to analyze mediation as a mechanism for the treatment of conflicts that allows the parties involved to choose their destinations, that is, besides being a promoter of democracy and a form of exercise of citizenship, it emancipates the subject. Thus, first, we will analyze the conflict in contemporary society and the forms of treatment. Next, we will study democracy and citizenship, from which the citizen has the power to manage and decide their controversies autonomously and independently. Finally, mediation will be examined as an instrument of emancipation and the exercise of citizenship, whose purpose is to demonstrate that the citizen through dialogue actively participates in the treatment of conflicts that are inherent to life in a democratic way. For that, the method of deductive approach and the indirect research technique were used through bibliographic research.

Keywords: Citizenship. Conflicts. Democracy. Emancipation. Mediation.

\section{Sumário}

1. Considerações iniciais; 2. Do conflito às novas possibilidades de seu tratamento; 3. Aspectos conceituais: sociedade democrática, cidadania ativa e participação social; 4. Por uma cultura da paz: a interlocução dos sujeitos como protagonistas de seu destino; 4.1 Breves aportes sobre a Teoria da Ação Comunicativa de Jürgen Habermas; 4.2 Mediação como instrumento de emancipação e de exercício da cidadania; 5. Considerações finais; 6 . Notas; Referências 


\section{CONSIDERAÇÕES INICIAIS}

A sociedade contemporânea urge por novos modelos jurisdicionais face à ineficiência e ineficácia dos meios tradicionais de tratamento ${ }^{1}$ de conflitos. Neste sentido, é cediço que o conflito é inerente ao ser humano, contudo, diante da plural sociedade, métodos diversos daquele centrado no monopólio estatal devem ser propostos com a finalidade de se obter respostas mais eficazes à conflituosidade vivida.

Assim, surge a mediação como um instrumento capaz de restabelecer a comunicação entre as partes, sendo o diálogo o fio condutor responsável por transformar o dissenso no consenso. Desta forma, a mediação constitui-se como a possibilidade de tratamento mais adequada à complexidade conflitiva atual, haja vista que propõe uma cultura da paz baseada na pluralidade de valores, de sentimentos e na existência de sistemas de vida diversos. Ela, então, reconstrói os laços sociais que foram rompidos, a partir do respeito das diferenças, do restabelecimento da comunicação e proporciona, não apenas a solução democrática do conflito, mas a emancipação do sujeito.

Enfim, a mediação pode recompor as relações sociais, pois ajuda os conflitantes a tratarem o conflito com autonomia, convergindo para o entendimento mútuo e ao consenso, sem que haja a necessidade da presença de um terceiro, o juiz, para tanto. Portanto, a mediação apresenta-se como uma possibilidade eficaz e adequada no tratamento dos conflitos não apenas em termos quantitativos, mas também qualitativos.

Face todos esses motivos, o presente estudo torna-se de suma importância. Assim, serão abordados alguns tópicos relevantes para o desenvolvimento e conclusões sobre o tema ora proposto, sendo o método de abordagem o dedutivo e a técnica de pesquisa indireta por meio de pesquisa bibliográfica.

\section{DO CONFLITO ÀS NOVAS POSSIBILIDADES DE SEU TRATAMENTO}

O conflito existe desde o início da civilização. Ele é intrínseco ao ser humano e aos grupos que o compõe, sendo que o seu surgimento ocorre a partir da vida em grupo. Ele é, pois, uma parte indiscutível do desenvolvimento da sociedade (ÁLVAREZ, 2003, p. 51), na medida em que ultrapassa as fronteiras do simples desencontro de opiniões, de posicionamentos, de valores, de culturas a fim de possibilitar transformações sociais inimagináveis (SPENGLER, 2012, p. 109).

Entretanto, definir a palavra conflito é extremamente difícil, razão pela qual não há uma noção unânime acerca de sua conceituação. Sabe-se apenas que possui como raiz etimológica a ideia de choque, de contrapor ideias, palavras, ideologias ou valores. Assim, para que exista conflito é imperioso inicialmente que as forças confrontantes sejam dinâmicas, que reajam entre si (MORAIS; SPENGLER, 2012, p. 45).

O conflito é, por conseguinte, uma forma social ensejadora de elaborações evolutivas e retroativas quanto às instituições, estruturas e interações sociais. Isso ocorre porque "o conflito não é uma realidade confinada ao âmbito apenas dos fenômenos humanos, individuais ou coletivos e sim uma realidade muito mais profunda" (SPENGLER, 2012, p. 110). 
Sendo oriundos das relações sociais, os conflitos caracterizam-se como "apenas um dos muitos meios de interação e convívio dentro de uma mesma sociedade". Contudo, eles não têm tão somente um sentido negativo, pois, a partir do momento que a sociedade é vista como um tecido de relações humanas que se modifica e se transforma sem, no entanto, cessar, "o conflito deve, necessariamente, fazer parte dessa constatação como meio através do qual muitas dessas alterações acontecem” (MORAIS; SPENGLER, 2012, p. 52).

Assim, o conflito passa a ter um caráter positivo na medida em que proporciona mudanças, estimula inovações, mas acima de tudo, enseja a manutenção da coesão do grupo no qual ele explode, ou seja, ele é o "meio de manter a vida social, de determinar seu futuro, facilitar a mobilidade e valorizar certas configurações ou formas sociais em detrimento de outras" (MORAIS; SPENGLER, 2012, p. 53). Neste sentido:

\section{[...] não obstante todo conflito ser considerado uma perturbação que rompe com a harmonia e equilíbrio constituidores do estado normal da sociedade, ele é importante, uma vez que impede a estagnação social. Por conseguinte, o con- flito não pode ser visto como uma patologia social: conflito é também vitalidade (SPENGLER, 2010, p. 245).}

Desta forma, possui funções sociais importantes, pois promove mudanças na sociedade em que está inserido além de estimular o desenvolvimento individual. Todavia, o importante não é aprender a evitá-lo ou suprimi-lo, ao contrário, "diante do conflito, a atitude correta é encontrar uma forma que favoreça sua composição construtiva". (CALMON, 2007, p. 25).

Não existindo harmonia no cumprimento espontâneo de preceitos e regras, momento em que surge o conflito, e, sendo desejada a sua solução, a jurisdição estatal aparece como meio ordinário para esse fim. Porém, como se demonstrará adiante, essa não é a única forma de solução dos conflitos.

Destarte, para tratar os conflitos que surgem na sociedade, o Estado, enquanto detentor do monopólio estatal utiliza-se do Poder Judiciário como sua força legítima. Tal legitimidade de decidir as controvérsias nasce, assim, "do contrato social no qual os homens outorgaram a um terceiro o direito de fazer a guerra em busca da paz". (SPENGLER, 2010, p. 278).

Logo, ao outorgar ao juiz a decisão de suas contendas, a sociedade fica inerte, pois espera que o Poder Judiciário resolva a lide, isto é, que diga quem tem mais direitos, mais razão, ou quem é o vencedor da demanda, ocorre então uma transferência de prerrogativas. (MORAIS; SPENGLER, 2012, p. 69).

Como consequência dessa mudança de responsabilidades, surge o que se denomina de explosão da litigiosidade, ou seja, uma crescente demanda de conflitos que eclodem no Poder Judiciário a fim de que o juiz diga a última palavra com base na lei. (SPENGLER, 2010, p. 285).

De suma relevância frisar que não obstante o Poder Judiciário decidir os conflitos que lhe são apresentados, isso não significa dizer que ele estará eliminando definitivamente aqueles, pois para que o conflito seja extirpado completamente, é necessário atacá-lo desde a sua raiz, isto é, não basta que o remédio aja apenas sobre a ferida, não atacando a causa, razão pela qual o principal problema da magistratura é que ela decide as lides "sem sentir 
os outros do conflito, encaixando-os num modelo normativo" (MORAIS; SPENGLER, 2012, p. 74).

A questão central é que ao interpretar a sua função de administradores da justiça os juízes, salvo exceções, não levam em consideração o que as partes envolvidas no conflito sentem ou almejam, fazendo com que ocorra uma verdadeira brutalidade com as partes, uma vez que "ao dizer o direito" de forma abstrata e segundo suas próprias convicções nem sempre os magistrados correspondem com o significado da palavra justiça compreendido pelos litigantes.

Assim, na esteira das formas ditas tradicionais de resolver controvérsias, existem possibilidades não jurisdicionais de tratamento dos conflitos, nas quais se busca acima de tudo a pacificação social. Essas novas modalidades de compor as disputas se diferenciam por atribuírem legalidade à voz das partes que buscam pelo diálogo tratarem a lide. (SPENGLER, 2010, p. 292).

Todavia, ressalta-se que esses métodos diferenciados não desejam,

\begin{abstract}
[...] propor a imediata e completa substituição da expressão tradicional, mas acrescentar fundamentos para que se abrevie o tempo em que se formulará uma nova ciência, mais ampla que o direito processual, para cuidar da pacificação social e de todos os meios para atingi-la ou restaurá-la. (CALMON, 2007, p. 27).
\end{abstract}

As formas autocompositivas de resolver os litígios representam "um ensejo concreto de participação popular na administração da justiça - e sua consequente democratização", sendo, da mesma forma, uma resposta "do atual modelo judiciário estatal". (MEDINA, 2004, p. 63).

Tal modelo de tratamento dos conflitos possui como sustentáculo o direito fraterno, o qual tem como pressuposto as regras de compartilhamento e de convivência mútua, onde se buscam maneiras de proteção dos direitos fundamentais a partir de métodos menos autoritários e impositivos, neutralizando dessa maneira os "choques" e minimizando os danos que a controvérsia pode causar. (GHISLENI; SPENGLER, 2011, p. 25).

Diante deste contexto, os métodos extrajudiciais são informais e se concretizam de uma maneira contrária àquela exercida pelo Poder Judiciário, no qual o Estado, na pessoa do juiz, decide qual das partes ganha ou perde a ação. Ainda, por esses meios as partes mantêm do início ao fim o controle do procedimento, bem como de seus eventuais resultados, são, pois considerados autônomos porque são regidos e conduzidos pelos próprios envolvidos e informais por não seguirem modelos e regras pré-estabelecidas.

Neste diapasão, de suma relevância mencionar que a expressão meios alternativos de resolução de conflitos originou-se das Alternative Dispute Resolution (ADR) que se desenvolveram nos Estados Unidos, a partir da década de 1980, apresentando-se como alternativas ao provimento jurisdicional estatal. (SPENGLER, 2010, p. 295).

Esses meios diferenciados objetivam modificar a cultura do conflito em uma cultura de pacificação social. Assim, nas sociedades contemporâneas surge a necessidade de se buscar métodos complementares ${ }^{2}$ de solução de conflitos não apenas com o intuito de de- 
safogar o Judiciário, mas como método eficaz de prestação de justiça e pacificação social. Nas palavras de Cândido Rangel Dinamarco, pacificar com justiça é o "mais elevado escopo social das atividades jurídicas do Estado". (DINAMARCO, 2003, p. 197).

Entre os meios complementares de tratamento de conflitos destaca-se a mediação, a qual será abordada e caracterizada em tópico específico, porém, a seguir serão feitos alguns aportes sobre a democracia e a cidadania para demonstrar que a partir desses dois conceitos o sujeito é capaz de se emancipar.

\section{ASPECTOS CONCEITUAIS: SOCIEDADE DEMOCRÁTICA, CIDADANIA ATIVA E PARTICIPAÇÃO SOCIAL}

O conceito de democracia e cidadania não é estático, ele se molda no tempo e se modifica de acordo com as características da sociedade em que se encontra. É fruto de um processo dinâmico, ou seja, que está em constante construção, haja vista que é o resultado da interação social.

Assim, atualmente, a democracia deve ser entendida não apenas como o conjunto de garantias institucionais, isto é, como uma liberdade negativa, mas sim como "a luta de sujeitos, impregnados de sua cultura e liberdade, contra a lógica dominadora dos sistemas". Ela é, pois, a política do sujeito. (TOURAINE, 1996, p. 24).

Sendo o sujeito o alicerce da democracia, ele é o cerne da soberania popular na medida em que a "ordem política é produzida pela ação humana". (GHISLENI; SPENGLER, 2013 , p. 50). Dessa forma, o poder do povo significa a capacidade reconhecida ao maior número possível de pessoas para viverem livremente e para construírem sua vida individual a partir da associação entre o que são e o que pretendem ser, bem como da resistência ao poder em nome da liberdade. (TOURAINE, 1996, p. 25).

Neste sentido, Amartya Sen distingue cinco tipos de liberdade: as liberdades políticas, as facilidades econômicas, as oportunidades sociais, as garantias de transparência e a segurança protetora, sendo que cada uma dessas espécies distintas de direitos e oportunidades, ajuda a promover a capacidade geral de uma pessoa, pois com oportunidades sociais adequadas, os sujeitos podem efetivamente moldar seu próprio destino e ajudar uns aos outros, "não precisam ser vistos como beneficiários de engenhosos programas de desenvolvimento". (SEN, 2000, p. 25-26).

Para que o cidadão se emancipe e se torne sujeito de si ele deve desvencilhar-se das amarras da dominação, momento em que deve saber visualizar os efeitos de poder que o circundam, pois "o efeito de poder se impõe desvirtuando a relação de maneira farsante, a gosto das artimanhas do poder, tendo por resultado principal evitar que o marginalizado se confronte". (DEMO, 2002, p. 261). Portanto, não apenas os regimes autoritários inibem a emancipação, mesmo nas democracias, o assistencialismo, o paternalismo e a tutela do Estado, aceitos que são pela maioria das pessoas por comodismo, tampouco permitem o desenvolvimento de uma cidadania plena. (GORCZEVSKI, 2011, p. 110).

Ter liberdade melhora o potencial das pessoas para cuidar de si e para influenciar o mundo. Neste contexto, Sen fala da importância da liberdade como aspecto da "condição de 
agente", entendido este como alguém que age e ocasiona mudança, ou seja, aquele cidadão que não fica apático diante dos obstáculos que surgem em sua vida. (SEN, 2000, p. 33).

Dessa forma, a democracia não deve reduzir o ser humano a ser apenas um indivíduo, deve reconhecê-lo como um cidadão livre, que faz parte de coletividades econômicas e culturais (TOURAINE, 1996, p. 29), por conseguinte, a democracia não está a serviço da sociedade ou dos indivíduos, mas dos seres humanos como sujeitos criadores de si mesmos, sendo a igualdade política "um meio de compensar as desigualdades sociais". (TOURAINE, 1996, p. 37). Propugna-se, em vista disso, por uma sociedade mais igualitária e menos excludente, isto é, a não indiferença. (GUERRA, 2012, p. 140).

É possível perceber então, a relação íntima existente entre democracia e cidadania, pois "a democracia se apoia na responsabilidade dos cidadãos". Assim, "a ideia de cidadania proclama a responsabilidade de cada um e, portanto, defende a organização voluntária da vida social contra as lógicas não políticas". (TOURAINE, 1996, p. 95-97).

Liszt Vieira assinala que:

A cidadania, definida pelos princípios da democracia, constitui-se na criação de espaços sociais de luta (movimentos sociais) e na definição de instituições permanentes para a expressão política (partidos, órgãos públicos), significando necessariamente conquista e consolidação social e política. A cidadania passiva, outorgada pelo Estado, se diferencia da cidadania ativa, na qual o cidadão, portador de direitos e deveres, é essencialmente criador de direitos para abrir novos espaços de participação política. (VIEIRA, 1997, p. 40) .

Portanto, a cidadania na contemporaneidade remete a ideia de uma cidadania ativa, onde "os cidadãos tornam-se protagonistas da sua própria história, deixam de ser objetos das iniciativas de outros e tornam-se sujeitos do seu futuro". (SCHMIDT, 2006, p. 1774).

Para que o sujeito se torne cidadão é imprescindível a conjugação de três elementos indispensáveis:

o primeiro é a resistência à dominação; o segundo é o amor de si pelo qual o indivíduo estabelece a sua liberdade como condição principal de sua felicidade e como um objetivo central; o terceiro é o reconhecimento dos outros como sujeitos e consequente apoio às regras políticas e jurídicas que proporcionam ao maior número possível de pessoas o máximo de oportunidades de viver como sujeitos. (TOURAINE, 1996, p. 172).

A correlação entre cidadania e democracia converge na medida em que esta ajuda os indivíduos a se tornarem verdadeiros sujeitos/cidadãos "capazes de resistir à dissociação entre o mundo da ação e o mundo do ser, entre o passado e o futuro". (TOURAINE, 1996, p. 176).

Nas palavras de Gorczevski, "cidadania pressupõe democracia, liberdade de manifestação, de contestação, respeito a todos integrantes da comunidade, aos seus credos, aos seus valores, às suas culturas". Contudo, ela não pode ser dada nem outorgada, ao contrário, somente pode ser alcançada pela participação, pela luta e pelo empenho dos próprios indivíduos interessados. (GORCZEVSKI, 2011, p. 110).

Assim, participação "não é ausência, superação, eliminação do poder, mas outra forma de poder", ou seja, é uma outra forma de intervir na realidade que passa por duas fases distintas: a autocrítica, que sabe reconhecer suas tendências impositivas, e pelo diálogo 
aberto com os interessados. (DEMO, 1996, p. 20-21).

Gorczevski afirma que:

\begin{abstract}
[...] com a autêntica participação ocorrem dois benefícios: um individual, que atinge a autoestima e permite que o indivíduo se desenvolva como cidadão, mais competente, mais responsável e seguro de si, ao mesmo tempo em que se dá um benefício social, a melhoria da organização e o funcionamento da comunidade através da democratização. (GORCZEVSKI, 2011, p. 117).
\end{abstract}

Na realidade, o que se almeja construir é um verdadeiro comprometimento do sujeito na busca do tratamento dos seus conflitos através do diálogo, da cooperação mútua, da paz. Enfim, pretende-se a emancipação do cidadão a fim de que este torne o mundo mais humano, sem que haja desinteresse, desprendimento, desdém e apatia. Que ele não seja indiferente aos problemas que lhe rodeiam, razão pela qual é imprescindível a participação. (GUERRA, 2012, p. 143).

Nesse cenário, a mediação é, pois, um importante instrumento não apenas de emancipação, mas também de exercício de cidadania, pois a partir dela as partes envolvidas tornam-se atores ativos no tratamento das controvérsias em que estão inseridas, ou seja, participam ativamente na construção do consenso.

Assim, é necessário tecer alguns comentários sobre a Teoria da Ação Comunicativa de Jürgen Habermas.

\title{
4. POR UMA CULTURA DA PAZ: A INTERLOCUÇÃO DOS SUJEITOS COMO PROTAGONISTAS DE SEU DESTINO
}

Como mencionado anteriormente, o conflito é inerente ao ser humano, constituindo-se como parte integrante da sociedade, principalmente da moderna. Dessa forma, diversos meios existem para dirimir e resolver as controvérsias existentes, porém nem todos proporcionam o tratamento democrático e consensual da lide através da interlocução e interação entre os sujeitos envolvidos como a mediação comunitária, a qual será objeto de apreciação na sequência.

\subsection{BREVES APORTES SOBRE A TEORIA DA AÇÃO COMUNICATIVA DE JÜRGEN HABERMAS}

O chamado mundo da vida ${ }^{3}$ onde ocorrem os conflitos é palco das relações interativas entre as pessoas. Estas passam por diversas fases: primeiro passa por gestos, depois transforma o comportamento dos envolvidos e, por último gera a interlocução entre aquele que fala e aquele que escuta. (COSTA; SILVA, 2011, p. 22). Todo esse processo resulta na "reconstrução da trama de discursos formadores de opinião e preparadores de decisão presentes no exercício da democracia em um Estado de Direio sociointegrador". (SPENGLER, 2010, p. 359).

O agir comunicativo relaciona-se com a racionalidade recíproca, ou seja, com a utilização do agir orientado para o entendimento (GHISLENI; SPENGLER, 2013, p. 60), portanto, a racionalidade comunicativa "exprime-se na força unificadora da fala orientada ao entendimento mútuo, discurso que assegura aos falantes envolvidos um mundo da vida intersubjetivamente partilhado". (HABERMAS, 2004, p. 107). 
A Teoria da Ação Comunicativa enseja, pois, a possibilidade de construir novas percepções para compreender a tão complexa e distinta sociedade. Evidencia-se então a relevância da interlocução entre os sujeitos no substabelecimento das relações interpessoais e sociais. Em outros termos, a ação comunicativa leva a crer que as relações entre as pessoas têm por finalidade não apenas a comunicação, mas o entendimento mútuo. (COSTA; SILVA, 2011, p. 23-24).

Desse modo, é possível dizer que:

\begin{abstract}
[...] a ação comunicativa apenas irá ocorrer quando houver um reconhecimento intersubjetivo e uma aceitação do ouvinte em relação àquilo que o falante profere, ou seja, quando há um processo linguístico de entendimento mútuo. Ao se entenderem uns com os outros, os atores edificam pretensões de validade, pretensões de correção e pretensões de sinceridade, capazes de construir um acordo de natureza reflexiva, pelo fato de terem chegado a uma convicção comum. Assim, a partir de um acordo racional a respeito de normas, distancia-se do decisionismo. (COSTA; SILVA, 2011, p. 24).
\end{abstract}

A partir do momento em que o sujeito exprime os seus sentimentos e sua opinião ele tem a possibilidade de resolver consensualmente e de forma autônoma os seus conflitos, sem utilizar-se do Estado. O agir comunicativo ocorre então a partir da prática do consenso, gerando compromissos numa estrutura na qual a coerção já não serve mais como elemento condutor do agir social em relações conflituosas (SPENGLER, 2010, p. 359), momento em novas modalidades de tratamento das controvérsias surgem.

A ação comunicativa, logo, é compreendida como uma espécie de ação social orientada pela comunicação, a qual possibilita uma efetiva democratização da sociedade e exercício da cidadania através de uma concepção discursiva da soberania popular, visto que os pactos comunicativos proporcionam uma participação mais ativa dos sujeitos, bem como viabilizam a criação de espaços comunicativos orientados para a formação democrática da opinião e da vontade, através da utilização de processos de entendimento mediados pela liguagem. (GHISLENI; SPENGLER, 2013, p. 61).

Neste contexto, a mediação de conflitos por ser um procedimento alicerçado no diálogo entre as partes, funciona como um mecanismo de solidificação do Estado Demcrático de Direito, pois oportuniza que os sujeitos se emancipem e se tornem cidadãos ativos, responsáveis por suas decisões.

Assim, a Teoria da Ação Comunicativa, proposta por Jürgen Habermas, possui grande importância no contexo em que se insere a mediação, pelo fato de:

\footnotetext{
[...] representar uma teoria crítica da sociedade e de pressupor que o espaço público ocupado pelos atores sociais é constituído de uma rede comucacional em que cada sujeito tem o momento para tentar externar os atos de fala, ou seja, o que está no ímpeto dos seus mundos [...] (COSTA; SILVA, 2011, p. 23).
}

A mediação então deve ser entendida como um meio de tratamento de conflitos que se consubstancia pela formação do consenso, de emancipação e de exercício da cidadania, sendo o diálogo a principal ferramenta utilizada pelos interlocutores, a qual será abordada a seguir. 


\subsection{MEDIAÇÃO COMO INSTRUMENTO DE EMANCIPAÇÃO E DE EXERCÍCIO DA CIDADANIA}

Havendo o dissenso os interlocutores buscam o restabelecimento do consenso 4 pela racionalidade comunicativa. Assim, o consenso pressupõe três ideias essenciais: escolha, confiança e razão que constituem juntas "o sinal de união entre os homens, de um comprometimento nascido das razões comuns e, sobretudo de uma prática inerente à democracia moderna". (SPENGLER, 2010, p. 366). É por isso que o consenso é entendido como uma estratégia democrática de tratar os conflitos.

Ao se livrarem das amarras da dominação e se abrirem à comunicação, os sujeitos podem cooperativamente evoluir mudando o seu mundo. Ao interagir e trocar experiências as partes participam ativamente na tomada de decisões reconstruindo os laços interrompidos pelo conflito. Essa reconstrução que parte do conflito para o consenso pode ocorrer pela mediação.

Assim, a mediação é uma maneira de restabelecer a comunicação rompida entre as partes formada pela posição antagônica instituída pelo litígio. Ela "facilita a expressão do dissenso definindo um veículo que possa administrar a discordância e chegar a um consenso comunicativo". (SPENGLER, 2010, p. 350). Neste sentido, ela também poderia ser definida como a forma ecológica de resolução de conflitos sociais e jurídicos na qual o intuito de satisfação do desejo substitui a aplicação coercitiva e terceirizada de uma sanção legal. (WARAT, 1998, p. 05).

É, por conseguinte "a arte de compartir" e tem como pressuposto o restabelecimento da comunicação entre as partes através de um terceiro imparcial denominado mediador. (WARAT, 2004b. p. 40). Sua meta é responsabilizar os conflitantes pelo tratamento do litígio, diminuindo as divergências, compreendendo as emoções reprimidas e buscando um consenso que atenda aos interesses de ambas as partes para ao final chegar à paz social. (SPENGLER, 2010, p. 322).

Possui diversas características dentre as quais se destacam: a voluntariedade, a confidencialidade, a flexibilidade e a participação ativa.

A voluntariedade decorre da aceitação por livre iniciativa ou aceitação das partes em participar do processo mediativo. A confidencialidade se caracteriza em razão das informações serem restritas ao âmbito das partes e do interventor, salvo autorização para publicidade. No que se refere à flexibilidade do processo, refere que a mediação não é um processo rígido, ou seja, não está adstrita a normas genéricas e pré-estabelecidas. E, por fim, o caráter participativo diz respeito à capacidade das partes, mediante uma atuação ativa, de buscar o consenso. (TAVARES, 2002, p. 68).

Logo, a mediação, como instrumento comunicativo, permite que as partes participem ativamente da construção do tratamento do conflito, comprometendo-se e responsabilizando-se pela decisão tomada, ou seja, é um verdadeiro exercício de cidadania, porquanto possibilita às partes sair da estagnação para chegar à mudança, transformando o sujeito em um cidadão ativo e emancipado que pode fazer suas escolhas e decisões. 
Ademais, a mediação é um mecanismo que estimula a participação individual promovendo a autonomia privada, o que faz com que ocorra a consequente emancipação, na medida em que cada mediando exprime suas opiniões, sentimentos e vontades, não necessitando de uma decisão imposta do ente estatal. Ocorre então uma mudança de cultura, visto que os sujeitos participam ativamente do processo democrático de solução do litígio.

Importante, diferenciar que existem duas espécies de participação, a consensual e a normalizada. A participação consensual visa manter o equilíbrio entre os indivíduos, sem privilegiar a maioria nem prejudicar a minoria, podendo as partes se manifestar sem que haja qualquer regra prescrita, isto é, todos participam para a construção do consenso. (SPENGLER, 2012, p. 181).

Já, a participação normalizada é regulada pela hierarquia. Assim, todos os problemas existentes que necessitem de decisão devem ser solucionados por um superior. Nesse tipo de participação as partes temem se expressar, o que faz com que apenas aceitem a decisão tomada. (SPENGLER, 2012, p. 182).

Nestes termos é possível identificar a mediação como uma prática comunicativa que gera participação consensuada, onde as partes deixam a inércia para chegar à mudança. (SPENGLER, 2012, p. 183). A participação consensuada faculta às partes se confrontarem e se pronunciarem sem constrangimento ou limitação de tempo, promovendo um real exercício de cidadania, pois o cidadão sai da sombra da decisão imposta pelo Estado-juiz para ser protagonista do seu próprio destino, em suma, emancipa-se.

Por isso, a prática da mediação configura um novo passo para a democratização da justiça, abrindo um horizonte de participação e autonomia, ao priorizar o restabelecimento do diálogo entre as partes envolvidas no conflito. Assim, a emancipação e exercício da democracia e da cidadania devem ser valores perseguidos e praticados cotidianamente para que o sujeito se torne um cidadão ativo responsável pela sua história.

\section{CONSIDERAÇÕES FINAIS}

O presente artigo abordou a análise da mediação enquanto instrumento de emancipação e de exercício da cidadania. Assim, para que o mesmo fosse possível foi necessário o estudo inicialmente dos conflitos e dos meios de tratamento, da democracia e da cidadania e, por fim da mediação.

O conflito é inerente a vida humana, entretanto é responsável por contribuir para a evolução da sociedade na medida em que rompe com a estagnação social. Assim, sendo desejada a solução do mesmo existem diversas possibilidades, entre elas a mediação.

Dessa forma, a mediação é um mecanismo que torna possível a extinção permanente de toda e qualquer disputa que surja diante da moderna e complexa sociedade contemporânea, pois restabelece entre as partes o diálogo, o que por consequência os responsabiliza.

Ela difere dos meios tradicionais, no qual o juiz é o responsável por dizer quem tem mais ou menos direitos, justamente por se caracterizar como um método dialógico e consensual em que os próprios envolvidos na contenda decidem a melhor forma de pôr fim ao 
litígio.

A mediação é enfim, um instrumento que estimula a participação e a autonomia individual, o que faz com que as partes não fiquem inertes esperando por uma decisão estatal, ou seja, os mediandos participam ativamente da construção democrática do tratamento do conflito, exercendo, pois, a cidadania, o que, por consequência, os emancipa.

\section{NOTAS}

1. Será utilizada, a expressão "tratamento" ao invés de "resolução" de conflitos, justamente por se entender que os conflitos sociais não são "solucionados" pelo Judiciário, no sentido de resolvê-los, suprimi-los, elucidá-los ou esclarecê-los, pois é rara a eliminação pelo Judiciário das causas, tensões e contrastes que os originaram. Assim, a expressão "tratamento" é mais adequada quando se busca tratar o conflito como medida terapêutica, buscando uma resposta satisfativa.

2. Diz-se que os meios extrajudiciais de tratamento de conflitos são complementares, haja vista que não substituem o Poder Judiciário na resolução dos litígios. Agem, entretanto, como auxiliares.

3. "Mundo da vida" de Jürgen Habermas compreende três dimensões diferentes: a) podendo ser avistado primeiramente como um mundo objetivo - enquanto conjunto de todas as entidades sobre as quais se possa produzir enunciados verdadeiros; b) o mundo social - como conjunto de todas as relações interpessoais legitimamente reguladas; c) e, por fim, o mundo subjetivo - visto como totalidade das vivências do falante, às quais este tem um acesso privilegiado. (SPENGLER, 2012, p. 166).

4. Para Habermas o consenso é o primeiro elo na formação da vontade coletiva, sendo oriundo de uma "tensão explosiva entre facticidade e validez". (HABERMAS, 2000, p. 599).

\section{REFERÊNCIAS}

ÁLVAREZ, Gladys Stella. La mediación y el acesso a justicia. Buenos Aires: Rubinzal - Culzoni Editores, 2003.

CALMON, Petrônio. Fundamentos da Mediação e da Conciliação. Rio de Janeiro: Forense, 2007.

COSTA, Marli M.M. da Costa; SILVA, Linara da. A importância do agir comunicativo na efetivação da justiça restaurativa em um contexto de alienação social. In: COSTA, Marli Marlene Moraes da; RODRIGUES, Hugo Thamir. (Org.). Direito \& Políticas Públicas VI. Curitiba: Multideia, 2011.

DEMO, Pedro. Participação é conquista: noções de política social participativa. 3.ed. São Paulo: Cortez, 1996.

DEMO, Pedro. Solidariedade como efeito de poder. São Paulo: Cortez; Instituto Paulo Freire, 2002.

DINAMARCO, Cândido Rangel. A instrumentalidade do processo. 11 ed. São Paulo: RT, 2003.

GHISLENI, Ana Carolina; SPENGLER, Fabiana Marion. Mediação de conflitos a partir do Direito Fraterno. Santa Cruz do Sul: EDUNISC, 2011.

GHISLENI, Ana Carolina; SPENGLER, Fabiana Marion. A mediação como instrumento de resolução de conflitos baseada na teoria da ação comunicativa de Habermas. Revista Pensar, Fortaleza, v. 18, n. 1, p. 
47-71, jan./abr. 2013. Disponível no site: http://ojs.unifor.br/index.php/rpen/article/view/2449/pdf.

GORCZEVSKI, Clovis. A necessária revisão do conceito de cidadania: movimentos sociais e novos protagonistas na esfera pública democrática. Santa Cruz do Sul: EDUNISC, 2011.

GUERRA, Sidney. Direitos Humanos e cidadania. São Paulo: Atlas, 2012.

HABERMAS, Jürgen. Facticidad y validez: sobre el derecho del Estado democrático de derecho em términos de teoria del discurso. 2.ed. Madrid: Trotta, 2000.

HABERMAS, Jürgen. Verdade e justificação: ensaios filosóficos. Tradução de Milton Camargo Mota. São Paulo: Loyola, 2004.

MEDINA, Eduardo Borges de Mattos. Meios alternativos de solução de conflitos: o cidadão na administração da justiça. Porto Alegre: Sergio Antonio Fabris, 2004.

MORAIS, José Luis Bolzan de; SPENGLER, Fabiana Marion. Mediação e Arbitragem: alternativas à jurisdição. 3 ed. rev. e ampl. Porto Alegre: Livraria do Advogado, 2012.

SCHMIDT, João Pedro. Exclusão, inclusão e capital social: o capital social nas ações de inclusão. In: REIS, Jorge Renato dos; LEAL, Rogério Gesta.(Org). Direitos Sociais \& Políticas Públicas: desafios contemporâneos. 6t. Santa Cruz do Sul: EDUNISC, 2006.

SEN, Amartya. Desenvolvimento como liberdade. São Paulo: Cia das Letras, 2000.

SPENGLER, Fabiana Marion. Da Jurisdição à Mediação: por uma outra cultura no tratamento de conflitos. ljuí: Ed. Unijuí, 2010.

SPENGLER, Fabiana Marion. A mediação comunitária enquanto Política Pública Eficaz no Tratamento dos Conflitos. In: LEAL, R; REIS, JR. Direitos Sociais e Políticas Públicas. Santa Cruz do Sul: Edunisc, 2011. Tomo 11.

SPENGLER, Fabiana Marion. Fundamentos Políticos da Mediação Comunitária. ljuí: Ed. Unijuí, 2012.

TAVARES, Fernando Horta. Mediação e conciliação. Belo Horizonte: Mandamentos, 2002.

TOURAINE, Alain. O que é a democracia? Tradução de Guilherme João de Freitas Teixeira. Petrópolis: Vozes, 1996.

VIEIRA, Liszt. Cidadania e Globalização. 7.ed. Rio de Janeiro: Record, 1997.

WARAT, Luis Alberto. Em nome do acordo: A mediação no direito. Florianópolis: ALMED, 1998.

WARAT, Luis Alberto. Surfando na pororoca: o ofício do mediador. Florianópolis: Fundação Boiteux, 2004b. V.3.

Recebido em: 30/07/2018

Aceito em: 05/10/2018 